\title{
3. The IEFG: role of a philanthropic affinity network within global education
}

\section{Megan Haggerty, Bronwen Magrath and Gordana Kelava}

If you were lucky enough to have the funds, how would you start on your journey to good grant-making in education? How would you go about choosing a project on which to focus? How would you measure your achievements and those of your grantees? How would you keep up with new developments and research in the education field? How would you find a group of peers to share ideas with, knowing that when you open your mouth at an education conference, or to a non-governmental organisation (NGO), that the expectation of money looms in the background? How could you ensure your work is not done in isolation but serves to strengthen the education sector and move the field forward?

This chapter explores the International Education Funders Group (IEFG), an affinity network of over 100 foundations set up in 2010 by a group of foundations who sought to answer some of the above questions. This chapter will look at the history, organisation, composition and activities of the IEFG in order to shed some light on the role of funder affinity networks in strengthening the collective work of education grant-making. These sorts of networks are rarely put under the spotlight and are often a bit of a mystery to outsiders. Yet they serve a crucial purpose as fora for knowledge-sharing and networking, and, by encouraging coordination among private donors, have the potential to improve the effectiveness and efficiency of education grant-making.

In the last 50 years, international development has shifted from predominantly isolated interventions to a more collaborative and multi-stakeholder approach that aims for systemic rather than one-off change (Chabbott, 2003; Menashy, 2015; Mundy, 1998). Simultaneously, philanthropy has evolved from a mostly charity-based model towards giving as a catalyst for social change and policy influence, what has been termed 'muscular philanthropy' (Bishop \& Green, 2010). These shifts, combined with the 
communications revolution of the internet, have led to greater cohesion among philanthropic actors, who are now more networked to each otherand to other global education actors - than ever before.

The IEFG provides an interesting case study of this new collaborative approach to global education and development.

\section{AFFINITY NETWORKS VERSUS DONOR COLLABORATIVES}

Philanthropic networks cover a vast range of types and engagements, beyond their binding thematic or geographic topic. The spectrum of engagement can range from simple information sharing and co-learning to strategic alliances - either formal or informal - all the way to more complex arrangements of pooled funding (The Philanthropy Initiative, 2009). As Grant Lewis (2011) notes, the complexity of collaboration increases as one moves up the pyramid (see Figure 3.1). Co-funding and pooled funding clearly demand more time and effort than information-sharing, but these 'higher order' forms of collaboration also require foundations to put aside some of their autonomy and brand recognition for the sake of increasing the size and efficiency of a particular grant.

At the loosest level of engagement are 'affinity networks' or 'affinity groups'. These are often formed as the first step in getting grant-makers together around an issue. Affinity networks are known for coordinating through information exchange, instead of coordinating through advocacy,

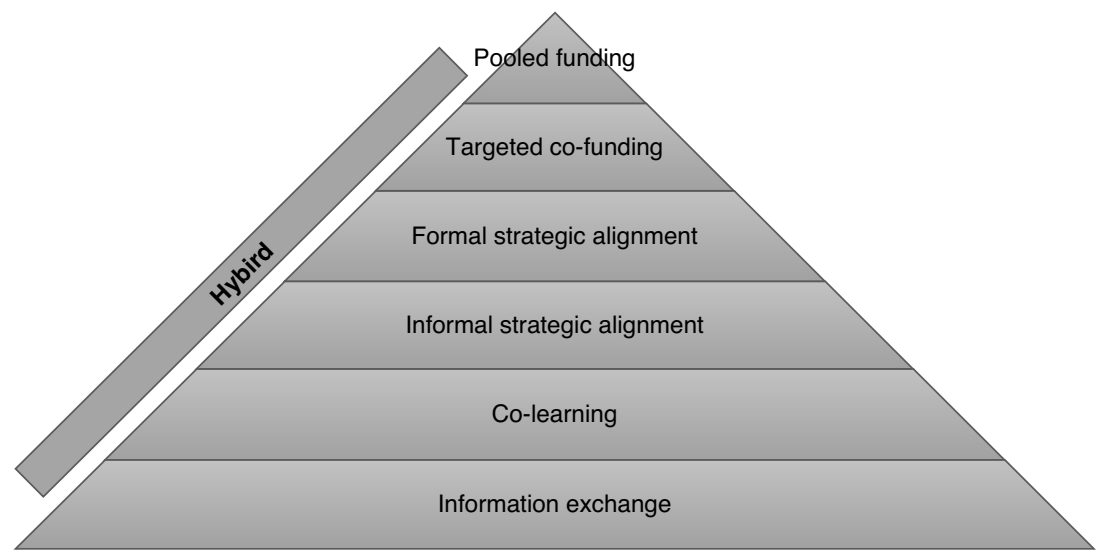

Figure 3.1 The spectrum of engagement, as described by Grant Lewis (2011) 
pooling of funds or aligning of grant-making. As Kennette Benedict (2003) notes, in her work for the MacArthur Foundation, 'In the affinity group mode, donors exist in an ecology of grant-making, where each may develop a niche within a grant-making field, each niche adding to the whole community of activity' (para. 9). Much like the fable of touching the elephant, each grant-maker contributes to this amorphous field, and by interacting in a group like the IEFG, they are able to see more parts of the elephant.

Affinity groups are the easiest groups to form, as they can be formal or informal in nature, and the members can develop plans of action as the need arises. However, the loose nature of these groups can also mean affinity networks are difficult to maintain (Benedict, 2003). The variance in affinity group size and mandate is significant. For example, some are linked by a common theme, such as the Elevate Children Funders Group, which brings together roughly a dozen funders focused on child well-being in the lower- and middle-income countries (LMICs); or the 25-year-old Human Rights Funders Network, which has over 1,500 members. Some groups are based on the funders' location (e.g., Philanthropy New York), while others are based on the funders' regional interests (e.g., the Africa Grantmakers' Affinity Group). ${ }^{1}$

Another way to think of affinity networks is to see them as a convening space (virtual or real) for grant-makers to meet each other, share knowledge and information and encourage collaboration. Similar to Jason Beech and Marianne Larsen's conceptualisation of spatiality in education (2014), this space not only exists as a place/time but also as a mode of transferring ideas and knowledge. Indeed, the participants contribute to and are shaped by their interactions with the convening space that is the affinity network. In turn, affinity networks become supportive learning communities that can offer partnership, mentoring, collaboration and expertise.

As the level of commitment and collaboration increases, affinity networks (or subgroups of these networks) may decide to form donor collaboratives, usually with concrete goals to affect a certain sector. These could be related to advocacy or policy goals or could seek to improve research or practice in a specific area. For example, the idea of the Partnership to Strengthen Secondary Education came out of an IEFG subgroup meeting, where six members decided to align targeted co-funding to systematically affect the secondary education sector in the lower-income countries, pooling USD 47 million from 2012-2018. The new Moving Minds Alliance similarly

\footnotetext{
1 Many affinity networks are managed by larger philanthropic support organisations, such as the Council on Foundations (https://www.cof.org/organization-type/affinity-group) and the European Foundation Centre (http://www.efc.be/thematic_network/).
} 
came out of a series of informal meetings between early childhood educators, who recognised the vacuum of early childhood development in the education in emergencies' space. Donor collaboratives, however, tend to be smaller and are more prone to ebb in size and activity. This is because the ability to have a concerted focus on a particular issue is difficult as foundations' interests and boards shift over time. However, they are also able to demonstrate their successes and impact more concretely than affinity networks, though this too is dependent on the political environment in which they operate (Fine, Lawrence \& Shultz Hafid, 2018). In contrast to affinity networks, much has been written about the lessons learned from donor collaboratives, both those thriving and those who have moved on. ${ }^{2}$

The IEFG could have chosen to become a donor collaborative in its early days; several of its subgroups may still choose to go this route, as trust develops and opportunities for collaboration emerge. However, overwhelmingly it has committed to a looser form of network that allows a wider umbrella of organisations to learn and benefit from the group, thereby hopefully impacting a larger number of grant-makers funding education in the LMICs.

\section{HISTORY OF THE IEFG}

The number and diversity of private philanthropic funders innovating and funding in education in the LMICs have increased significantly in the past decade, in step with new opportunities for these players on the global stage. From the invitation to foundations to have a seat on the board of the Global Partnership for Education (GPE, then known as the Fast Track Initiative) to the creation of the International Commission on Financing Global Education Opportunity (the Education Commission), space has been opening up for foundations to individually and collectively engage on the global stage.

Yet, until the formation of the IEFG, there was no independent space where private philanthropic funders working in education in the LMICs could learn from each other, share information and improve their grantmaking. In this context of urgent need and significant opportunity, private grant-makers started to meet up in 2003 at side meetings during gatherings where foundations were likely to be present, such as the UN General

2 The learning around donor collaboratives is captured in publications such as Lessons from a ten-year funding collaborative: A case study for the Partnership for Higher Education in Africa (Parker, 2010); A handbook for funder collaborations (Zisser, 2014); and Lessons in funder Ccollaborations (Huang \& Seldon, 2014). 
Assembly Week and the Comparative International Education Society conferences. Most of these meetings were voluntarily organised above and beyond the work responsibilities of several Program Officers at the Hewlett Foundation, which was at the time heavily involved in implementing its Quality Education in Developing Countries initiative. It was at this time that philanthropy in education was evolving from targeting charitable schools or experiments to beginning to look at systemic change and the role foundations could play in catalysing this change. It was recognised that the challenges faced would not be met with isolated, individually funded initiatives, but that sharing knowledge and intelligence on the field might help move the needle of change.

In 2010, six of these funders decided to pool funds and hire a consultant to figure out what a network could look like and who would be interested in participating. Out of this initial organising, in April 2011, representatives of 20 education funders agreed on the organisation and mission for the new International Education Funders Group (IEFG). The group grew to over 40 members in January 2012 and reached over 100 members in 2017, growing almost exclusively by word of mouth. The majority of new members are relatively new to the field of education (and sometimes new to philanthropy), which presents good opportunities for partnering and encouraging good practice in the field.

Since 2010, a wave of other groups targeting foundations in international development and/or global education have arisen. Most involve bilateral funders as well as grant-makers. Some have focused on specific initiatives in education, such as Building Evidence in Education $\left(\mathrm{BE}^{2}\right)$ or the Global Metric Task Force, which has fed into Brooking's Center for Universal Education Donor Network. Others have centred around grant-makers' engagement in and with organisations, such as OECD's netFWD and the World Bank's Foundation Advisory Council. Each of these is important in increasing foundation engagement in the education sector globally, as well as increasing the density of information flows and policy change. However, the IEFG stands apart from them for its independence and foundation-led focus, as well as for its size.

\section{THE ORGANISATION}

The main purpose of the IEFG is to help private grant-makers support basic education in the LMICs, have a stronger voice and be a catalytic force in the field of global development and education. This can be achieved by improving their strategic analysis and thinking, informing and assisting their grant-making and providing opportunities for collective learning 


\section{Table 3.1 IEFG sub-thematic groups}

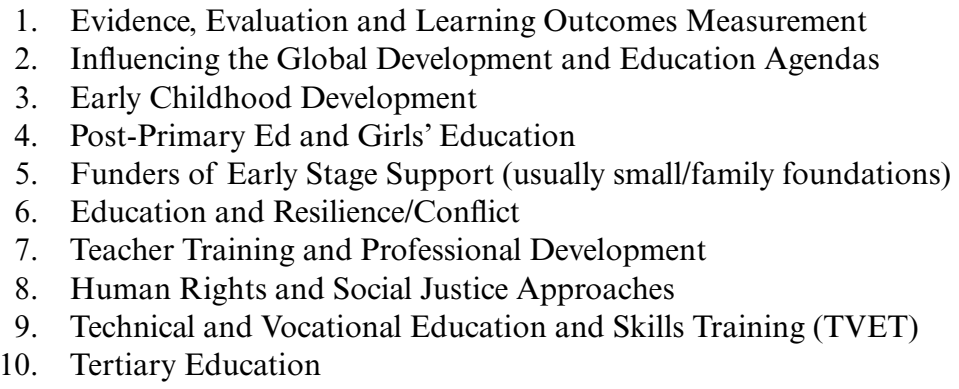

and action. It is best thought of as a convening space where members bring forward ideas and energy to discuss, collaborate and build the field.

The group has defined its parameters as basic education-including early childhood through secondary - and touching upon adult education, non-formal learning and youth and skills. In total, there are 10 thematic subgroups within the IEFG, shown in Table 3.1, with new ones emerging regularly in response to global needs and development. These ebb and flow dependent on member inputs. In 2018, after calls from its members, the IEFG expanded its remit from basic education to the education continuum found in the Sustainable Development Goals and opened a tertiary education subgroup to reflect this change.

Two major principles that the group endeavours to abide by are (a) to be member-driven, not Secretariat-driven and (b) to let form follow function, meaning that organisational shape of the IEFG evolves as the activities and needs of the IEFG membership evolve. It is designed to be nimble and flexible. As such, there is no head-office, and the group runs on strictly voluntary membership contributions. Its Secretariat is small and limited, with a Coordinator, Program Officer and Program Administrator, all of whom work part-time. This limited staffing, in turn, necessitates the active participation of members to make the network function, which has an added benefit of building collaboration and trust in the group through interaction. However, as time is at a premium, it also restricts the Secretariat's ability to build the organisation to engage in new areas of activities (for example, supporting specific subgroups that want to move an initiative collectively forward).

A third major principle is that the group is a 'no-pitching' space. In principle, this means that neither members nor guest NGOs are permitted to solicit funds or partners during IEFG events. Indeed, if a member has 
a funding idea they want to share, they are requested to go through the IEFG Secretariat to help facilitate connections. This 'no pitching' principle has the effect of focusing the meetings on ideas, instead of money flows, and also helps build trust within the group, as IEFG members are free to speak their minds, without being targeted for certain projects. In practice, however, there is significant collaboration, co-funding and informal pitching that goes on during the side meetings around IEFG events. The impact of these side conversations and informal networking is unknown, but anecdotally, it is one of the features that IEFG members appreciate within the community. In the last year, the IEFG has freed up a limited number of spaces in its newsletter and online portal where members can present ideas for collaboration or co-funding; however, on the whole, it carefully guards its space for open ideas exchange and knowledge-building.

The IEFG is led by a voluntary Steering Committee of nine to 12 representatives of member organisations who teleconference once a month to direct the Secretariat, make decisions on new members and decide the strategic direction of the group. Each member commits to sitting on the Steering Committee for three years, with roughly one-third of the committee changing hands each year. This has ensured that new ideas always arise within the Steering Committee and has also spread responsibility for the well-being of the network beyond the original founding members. The Steering Committee purposely mimics the diversity of the IEFG in its composition, seeking new members to fill gaps in geography or type of engagement to reflect the needs of all different types of funders in the group.

\section{SO, WHO IS IN THE IEFG?}

The IEFG does not publicly publish the list of its members. This is not out of a will to be an 'insiders' group, but rather to respect the needs and limits of IEFG members. For example, some members who fund education as a human right opt to be anonymous, in order to help protect their grantees from persecution. Other foundations have a small staff and do not want to be inundated by requests for funds. Others, while open about their funding to education on their websites, simply do not want to be part of a list of education funders. As such, this section talks about the general trends within the IEFG membership and the breadth of its work.

The IEFG is an umbrella of philanthropic actors in the education sector space, who are diverse in size, geography and engagement. It grows, through word of mouth, at a rate of about one foundation per month. 
Because it does not do advocacy and focuses on being a convening space for ideas, members are also more likely to come from a wider ideological stance than most groups.

In terms of size, the IEFG members range widely. The minimum criterium is to grant at least USD 50,000 per annum in education to an LMIC; however, these smaller members range from family foundations to charities who serve as intermediaries that re-grant funds to community-based organisations operating in-country. Some of these smaller organisations give upwards of 60 grants per annum, whereas others focus on contributing to three or four projects in total. Medium and large foundations are similarly diverse in their funding and range from private foundations to corporate foundations, and in a rare case reversing the trend, to a corporate foundation that owns the company. Most of these members either have been gifted an endowment, are given amounts by their live-benefactor as needed or receive a proportion of the profit from their related company. A few are banks that reach out to their high-net-worth individuals or donor-advised funds who work with anonymous funders on an educationfocused programme. Also included in the group are some Corporate Social Responsibility arms of corporations, provided that the grant-making they do is philanthropic and not connected to the growth strategy of their company.

Not included in the IEFG are those with business interests in education, whether they are foundations, NGOs or companies. So, for example, corporate foundations whose education grant-making is closely connected to the financial interests of their corporation are generally not admitted to the IEFG. For those with business interests in education, the Global Business Coalition for Education (GBC-Ed) offers a different community for engagement.

Also, not included are organisations that primarily exist to solicit funds from foundations. Although some IEFG members do solicit funds as part of their work, they must also be grant-makers in their own right and accept the norms of the group to not use the IEFG space for pitching.

Although all IEFG members have a common goal of grant-making to education in the LMICs, there are trends that show diversity within the group. About a third of members are headquartered in Europe, another third in the United States, and a final third are spread throughout other parts of the world, including Australia, East Asia and Latin America, with a sizeable number of foundations based in the Middle East or in one of the BRICS countries (Brazil, Russia, India, China or South Africa). Perhaps not surprisingly, this mapping of foundation headquarters mirrors the flow of capital in the current global system (Organisation for Economic Co-Operation and Development, 2018). It also speaks to the fact that the 
IEFG was started by U.S. and European foundations and has grown by word of mouth.

Local funders-funders who focus on grant-making in the country where they are headquartered - are a growing body within the IEFG, although most that fit this category tend to emerge in middle-income countries, not low-income countries. The local foundations bring their local expertise, which is useful to other IEFG members who engage in the region. In turn, their main reason for joining the IEFG is to learn about the international context and trends, touch on international research or engage in global policy dialogue.

The IEFG is aware of the need to ensure that its composition is aligned to its international aim. If it is to have the word International in its name, then surely more foundations from more countries should be included in the group, particularly those that are based in the LMICs and have a lived experience in the local context. But trust (as explored further down) appears to be an important ingredient in drawing new foundations to the group. If the IEFG Secretariat approaches a foundation who has not yet been recommended to it by one of its members, the relationship usually falters. However, if an interlocutor, such as another foundation or a known consultant, recommends that a foundation joins the group, it often becomes a strong, active member. The IEFG is actively looking for members based in the LMICs, in order to diversify and strengthen the group.

In terms of geography, about half of all IEFG members grant to Africa, with a clear focus on India and South Africa as well. The Syrian refugee crisis also tends to be a geographic hot-spot for grant-making in recent years. Beyond that generalisation, members' grant-making tends to be quite diffuse around the world, including grant-making to Asia, Latin America and the Middle East.

When the IEFG mapped where members were grant-making, a quick glance at the map showed the colonial influences of the flow of grantmaking. It should not be surprising that the 'donor darlings' (for example, India, Tanzania, Uganda and Kenya) came out with the largest number of IEFG members funding in these countries (see Figure 3.2). Perhaps not surprisingly, Anglophone foundations tended to focus on Anglophone countries; Lusophone on Lusophone countries; Francophone on Francophone countries. However, this does raise the question of whether foundations are grant-making in the countries that are furthest from achieving education or whether we are part of a system that continues to privilege some countries over others. 

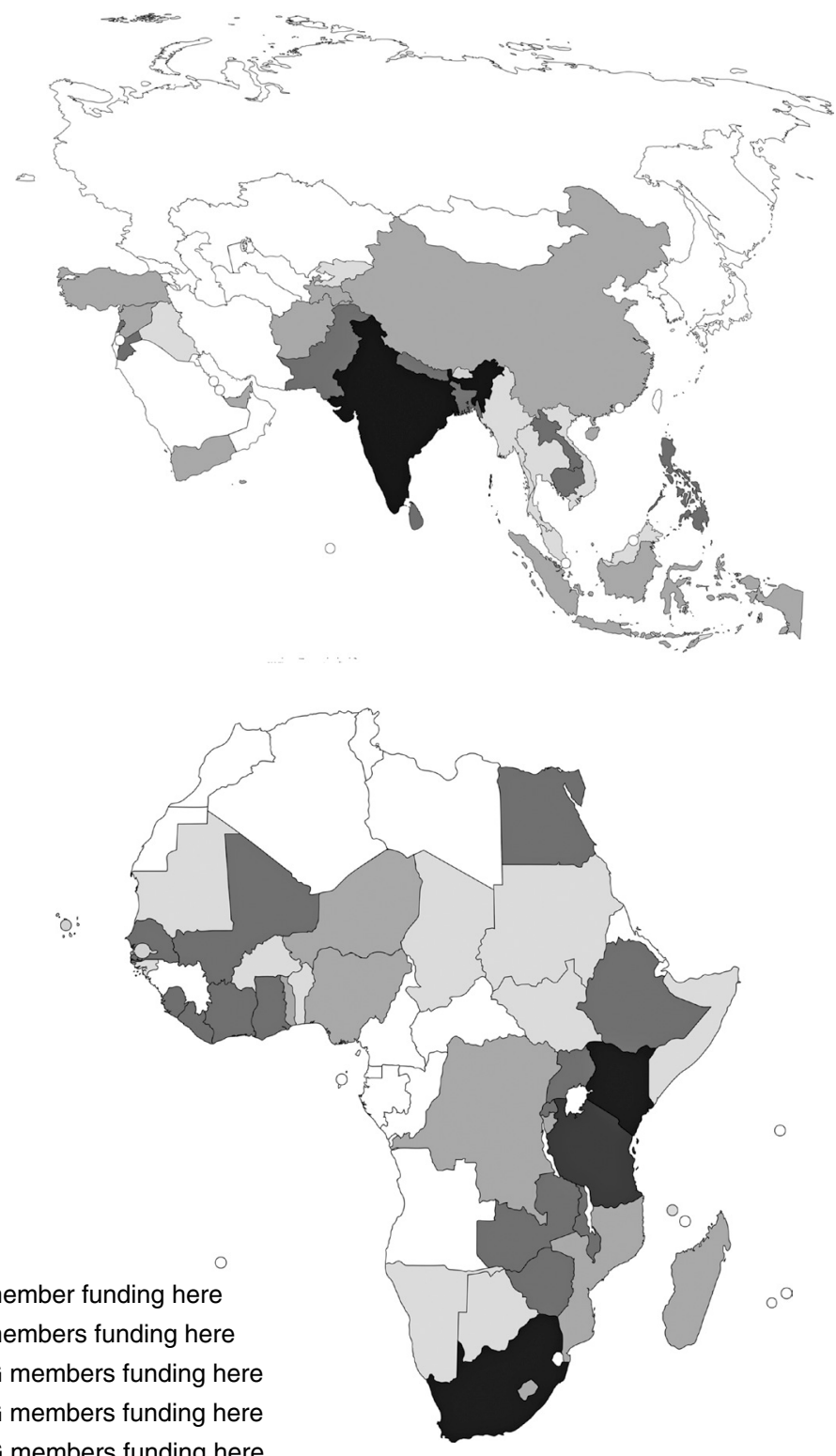

$\square 1$ IEFG member funding here

$\square 2$ IEFG members funding here

$\square$ 3-5 IEFG members funding here

-6-9 IEFG members funding here

-10+ IEFG members funding here

Source: Maps generated using Minas (n.d.).

Figure 3.2 Maps of IEFG members granting to primary education in Asia and Sub-Saharan Africa 


\section{WHAT NEED DOES THE IEFG FILL FOR FOUNDATIONS?}

As a member-led organisation that operates solely on voluntary contributions (where members decide individually how much to give), the IEFG's existence is due to the value it brings to its members. What does the IEFG give that its members cannot get elsewhere? In many ways, the IEFG responds to gaps it sees - and that members identify - in the field of global education philanthropy: a lack of opportunity for grant-makers to share information, collaborate or co-fund; and a perceived information overload' that makes it difficult for foundations to stay on top of the latest research and innovations.

Over the years, and through members' suggestions and feedback, the IEFG has identified three streams of work that provide insight not only on the value of the affinity network but also on the state of philanthropy in education at present. These streams of work include sharing information, providing depth and context to members' work and building a community of trust.

\section{Sharing Information}

First, the IEFG serves as an efficient way to share information for a group that needs timely information, but often finds it difficult to keep up. The art of grant-making requires a programme officer to keep up with the larger trends of the field, as well as the implementation challenges in the contexts in which they work. Balancing between the 'big picture' and 'nitty-gritty' allows grant-makers to assess whether the grants they are making contribute to the educational change they would like to see and whether a particular $\mathrm{NGO}$ /research centre/government agency is the right one for the job. This requires a huge amount of information and networking to do properly. The IEFG helps reduce this burden both through its information sharing and information networking.

In terms of information sharing, the IEFG puts out an e-Update/ Newsletter twice a month. Information is both collated from the web, as well as contributed by IEFG members as they come across research, events, blogs and policy pieces of interest. This e-Update has an opening rate of 43 per cent, showing the need foundations have for this type of quick information sharing. (One can register for the public version of the e-Update on the IEFG website.) Information is also shared between members through a secure online chat-group where members can post questions, comments or information to the whole group or to smaller subgroups with a shared regional or thematic interest. 
The IEFG Secretariat also plays a key role as a 'go-between' connecting like-minded foundations, as members often seek assistance linking with others in the network. This is particularly true for new members, new foundation staff or those moving into a new area of work. The IEFG works to encourage an informal buddy-system so that members are not left fumbling in the dark.

\section{Providing Depth and Context to Members' Work}

Second, the IEFG serves as one of the global spaces where foundations can try to frame the bigger issues they are dealing with. In small and medium-sized foundations, programme officers are often the only staff to work in this particular field or area of grant-making. This creates a challenge similar to that faced by academics, where their work is often strengthened by dialogue with peers outside their offices. Larger foundations often have a number of staff working on a theme, but in their case, they may want to influence the ideas of other grant-makers (e.g., to push for more attention on quality, not access) or find like-minded organisations and individuals to work with. The IEFG helps foundations frame these bigger issues through its bi-annual member meetings. Each meeting is focused on a different theme, which helps foundations grapple with that particular theme and build their knowledge. Themes of the past few meetings have included 'Equity', 'Social Emotional Learning', 'Education and Technology', 'Monitoring Evaluation and Learning', 'Education and Resilience', and so on. These two- or three-day member events only provide snapshots in time of these issues, but through networking with the speakers and other IEFG members, members are better able to map the knowledge that they need and understand some of the critical junctures that they should consider if they choose to improve their grant-making practice in that particular area.

While these IEFG bi-annual meetings sound very similar to roundtables or research symposia, and indeed they are modeled on that type of learning, there is a difference. IEFG meetings are non-competitive, closed spaces where only foundations and a few guests gather, no pitching is allowed and foundations can relax to be in learning mode, instead of posturing mode. This is an important distinction, as in meetings held by think tanks or at academic conferences, foundations have a tendency to remain silent. This reticence is for two reasons: fear that the question they ask will be seen as representative of a particular angle of their foundation's work or that their time during the coffee break will be spent with opportunistic, well-intentioned grant-seekers, instead of in discussions and debates on the ideas they have just encountered. 
This role of framing the bigger picture has led the IEFG into the realm of global policy. The IEFG purposely does not directly influence education policy agendas. Practically speaking, this is because IEFG members are so diverse that there is little we could say with a unified voice. However, for many years, the IEFG has informally asked foundations to volunteer to attend global meetings on the community's behalf (such as the GPE Replenishment Campaign or the Humanitarian Summit in 2017) and report back to the group on the proceedings. Often these IEFG volunteers are already planning to attend the event, and the added value is making the connection to report back to the group, so a larger number of foundations may benefit from the knowledge. Individual IEFG members then take this knowledge to inform their own strategies in the education policy arenas.

The IEFG is also increasingly involved in generating and/or supporting the hosting of the foundation constituencies who have seats on governance bodies within various global organisations/mechanisms and passing on information from these organisations/mechanisms to the wider community of foundations. As global bodies such as the GPE, Education Cannot Wait and UNESCO's SDG4 Steering Committee have expanded their governance structures to include foundation representatives, the IEFG has been asked by its members to help organise constituencies so that elected or appointed foundation representatives can get input from their fellow foundations. These constituencies are not limited to IEFG members (as the foundation world is wider than the IEFG membership). In some instances, the representative reaches out informally and only when input is needed. In other instances, a formal democratic process is established to allow for input into specific governance decisions, especially those that may open up opportunities for, or otherwise impact, foundations. Form follows function in these cases.

Of the various bodies, the IEFG has been most involved in ensuring a foundation voice within the GPE. One IEFG member sits on the GPE board, while several others serve on various board committees within the GPE. All representatives feed back reports and outcomes from board and committee discussions and identify opportunities for input from the wider foundation constituency. They have been instrumental in the creation of the GPE's Private Foundation Engagement Strategy, the first such strategy between the GPE and one of its board constituencies. For the last few years they have been working with the GPE to find ways that foundations can align their work or directly partner with the GPE through its newly emerging Knowledge and Information Exchange (KIX) programme and Advocacy and Social Accountability (ASA) mechanisms at the global level or ways they can better activate their local NGO partners in the GPE Local Education Groups at the national level. The IEFG and the GPE Private 
Foundations' Constituency, therefore, offer a way for foundations to offer their unique assets and approaches, such as co-creation and catalytic action, to the changing nature of humanitarian and development aid in education.

\section{Building a Community of Trust}

Third, and perhaps most crucially, the IEFG has created a friendly community of trust, where foundations can draw upon each other for advice in the actual grant-making world.

One of the key Hewlett Program Officers who shepherded the IEFG in its early days, Lynn Murphy, explains, 'Foundations are like migratory birds. They flock together and scare easily' (personal communication, 10 August 2018). Each foundation may go out alone to fly its own path, but it often wants to know where it is flying in relation to its peers. If it tries a new direction, it wants to know if anyone else is trying it and wants to flag its success or seek (troubleshooting) advice regarding the new path. However, most foundations will stick to the direction of the flock, creating the influx of funds around popular themes of work or well-known NGOs. The IEFG, in turn, creates a space where foundations can talk about those new journeys or explore a new or emerging area of grant-making. Its collegial atmosphere also simply builds relationships which over time increases that trust.

As far as the observation that foundations 'scare easily', this is not universally true for philanthropy, but one can see trends. Most foundations can relate to stories where a good programme was not taken up because the request for money was brought in too quickly. Whereas foundations may be sceptical about the claims of a particular project, they will be less sceptical if it comes recommended by a fellow foundation. On the whole, foundations are more likely to trust the recommendations of their foundation peers than those outside the network, and they use the informal relations with fellow grant-makers in the IEFG_-often built up slowly over years - to scope out new projects and ideas.

The IEFG and its members recognise the value of encouraging collaboration between foundations in order to avoid replication and improve the efficiency and effectiveness of grant-making. At the same time, the sense of trust results in members feeling reassured that they are not being "pitched to' by colleagues looking for collaboration or co-funding opportunities. To cater to these two needs, the IEFG has created some space for members to explore opportunities for collaboration during face-to-face meetings and in virtual communities.

The philanthropy world is often criticised as being quite changeable. There are many examples of foundations who have moved out of a field 
or switched the type of projects they are supporting. For the programme officers within those organisations, the IEFG offers a community to connect to and that sometimes offers advice on how to help advocate for their ideas within their boards or advisory councils. It also offers a pathway for those who are new to or considering grant-making in education, by connecting them to relevant peers in the same geographies or subgroups.

This trust also enables foundations to have difficult discussions on issues that members fundamentally disagree upon. Nowhere is this more apparent than in the issue of private sector involvement in education. The IEFG includes members that are fully supportive of active private sector engagement, including supporting the development of low-cost private school chains or financial literacy for mom-and-pop private school operators. On the other hand, some IEFG members actively fund advocacy against the privatisation of education. Over the years, the IEFG has tried to broker conversations that move past this perceived ideological binary, so that the two sides could better understand the rationale behind their work. This, it is hoped, helps bring a critical reflection to both sides of the work. The extent to which these dialogues have been helpful is unknown. Attribution is a sticky business, but IEFG members continue to push for similar conversations as time progresses, suggesting that this middle-of-the-road dialogue is helping to push the boundaries of members' thinking.

\section{THE ROAD AHEAD: NEXT STEPS AND CHALLENGES FOR THE IEFG}

The IEFG is a growing network, with over 100 member organisations and new members joining monthly. Will this growth change the dynamics of a group that has been built on trust and personal connections? The IEFG must ask itself to what extent it can grow and what limitations it may face as an affinity network. An ongoing challenge is - and will be-managing the wide diversity of members, each of whom is an autonomous foundation. As a member-led network, overcoming this challenge is critical to getting clarity and consensus on key issues, prioritising topics for co-learning and joint action and defining the grant-makers' value-add to the global effort to improve education access and quality.

Starting in 2017, the IEFG has become increasingly outward-facing, as we have been growing our relationships with other global education players such as the GPE, the Education Cannot Wait Fund, the SDG2030 Steering Committee and NORRAG. This raises a challenge of representation: When the IEFG co-sponsors events or provides input 
on an external strategy, are we representing our membership as a whole? Or are we speaking on behalf of the Secretariat and Steering Committee? Although our steering group is deliberately diverse, a growing network is increasingly difficult to represent. Yet, having the IEFG present at these fora is an important legitimising force for our network and for a collective philanthropic voice. In the coming years, we will need to grapple with the challenge of representation to ensure that our member-led focus is strengthened rather than splintered by our growing mandate.

A broader challenge faced by the IEFG (and other actors in the education sector) is that aid to education has stagnated in recent years and appears to be slipping off the priority list for many donors. The IEFG is concerned about these changes to the funding landscape. In response, we have decided to make it an organisational goal to help increase philanthropic attention to basic education in the LMICs within our sphere of influence. In the future, we hope to highlight how the IEFG can play a convening role by using its own networks, and the networks of its members, to help increase funding for education. Yet, we will need to tread carefully in this endeavour; as noted, the IEFG is not an advocacy organisation and it deliberately remains politically neutral because of our membership diversity.

The role of private funders in global education is not without controversy, and the IEFG has done little to engage in wider debates about the role of philanthropy in education. In part, this is due to our role as a 'safe space' enabling education grant-makers to network and share information, which precludes conversations happening outside our closed doors. The IEFG's involvement in the NORRAG Philanthropy in Education Symposium series is an opportunity to begin this conversation.

It is important that education grant-makers understand the critical debates in the field and are aware of the potentially negative consequences of their growing political influence. At the same time, critics should not dismiss philanthropy as a bit-player or-worse - as an arm of corporate marketing. The diversity of education philanthropy, as well as the real gains these actors have made in global education, deserves recognition as well as robust analysis. It is essential that genuine engagement is fostered between the philanthropy sceptics and the believers if we are to move the field forward together. The IEFG welcomes the opportunity for engagement and looks forward to continuing the conversation.

\section{REFERENCES}

Beech, J., \& Larsen, M. A. (2014). Replacing old spatial empires of the mind. European Education, 46(1), 75-94. 
Benedict, K. (2003). Foundation collaborations. Retrieved August 23, 2018, from https://www.macfound.org/press/publications/foundation-collaborations/

Bishop, M., \& Green, M. (2010). Philanthrocapitalism: How giving can save the world. New York, NY: Bloomsbury.

Chabbott, C. (2003). Constructing education for development: International organizations and education for all. London, UK: Routledge.

Fine, M., Lawrence, S., \& Shultz Hafid, M. (2018, April 9). (Re)thinking funder networks and collaboratives. Stanford Social Innovation Review. Retrieved August 23, 2018, from https://ssir.org/articles/entry/rethinking_funder_networks_and_colla boratives\#

Grant Lewis, S. (2011). Lessons from donor collaboratives [PowerPoint slides]. Retrieved August 23, 2018 from archives of the IEFG.

Huang, J., \& Seldon, W. (2014). Lessons in funder collaborations. Los Altos, CA and Boston, MA: The Packard Foundation and The Bridgespan Group. Retrieved June 20, 2019, from https://www.packard.org/wp-content/uploads/2014/07/Les sons-in-Funder-Collaboration.pdf

Menashy, F. (2015). Understanding the roles of non-state actors in global governance: Evidence from the Global Partnership for Education. Journal of Education Policy, 31(1), 98-118.

Minas. (n.d.). Mapchart.net [Website]. Retrieved June 20, 2019, from https://map chart.net/

Mundy, K. (1998). Educational multilateralism and world (dis)order. Comparative Education Review, 42(4), 448-478.

Organisation for Economic Co-operation and Development. (2018). Private philanthropy for development. Paris, France: The Development Dimension, OECD Publishing. Retrieved June 20, 2019, from https://doi.org/10.1787/9789264085 190-en

Parker, S. (2010). Lessons from a ten-year funding collaborative: A case study for the Partnership for Higher Education in Africa. Retrieved June 20, 2019, from http:// fundingadvocacy.issuelab.org/resource/lessons-from-a-ten-year-funder-collaborati ve-a-case-study-of-the-partnership-for-higher-education-in-africa.html

The Philanthropy Initiative. (2009). Donor collaboration: Power in numbers. Boston, MA: Author. Retrieved June 20, 2019, from https://www.tpi.org/learning-center/ donor-collaboration-power-in-numbers

Zisser, O. (2014). A handbook for funder collaborations. Herzliya, Israel: Jewish Funders Network Israel. Retrieved June 20, 2019, from https://d3n8a8pro7vhmx. cloudfront.net/jfn/pages/269/attachments/original/1484602550/jfn_handbook_for _funder_collaborations.pdf?1484602550 